\title{
A Pilot Study on the Psychosocial Health and Living Quality of Left-Behind Children in a Remote City of China
}

\author{
Bin $\mathrm{Li}^{1,2, *}$ Steven $\mathrm{Chu}^{3}$, and Hongfei Zhong ${ }^{3}$
}

\begin{abstract}
Purpose: With the rapid economic development, China has undergone a large-scale migration, with many children left behind due to parental migration for better income. Little is known about the psychosocial health and living quality of the Chinese left-behind children (LBC) in remote cities, so this study aims at investigating the emotional and behavioral problems as well as the living qualities of $L B C$ in remote cities of China.

Methods: In this pilot cross-sectional study, 45 schoolchildren (10-12 years old) from Guiyang, a remote city in China, were enrolled in the sampling. The Strength and Difficulties Questionnaire (SDQ) and Quality of Life Scale for Children and Adolescents (QLSCA) were used to evaluate the psychosocial health and living quality. The differences between LBC and control children and correlation factors were analyzed in this study.

Results: LBC had a statistically significantly higher score in SDQ than in the control group with $p$-values that were all $<0.01$. The prosocial score in LBC was significantly lower than that of the control children $(p<0.01)$. The scores on QLSCA were significantly lower for the LBC than for their counterparts $(p<0.01)$. The emotional and behavioral problems (SDQ scores) and the living quality (QLSCA scores) are highly correlated.

Conclusion: This preliminary study identified the severity of the psychosocial problem and the lower living quality with $L B C$ in the remote city of China. This problem may relate to the lower education level of their caregivers. The LBC in remote cities of China need more psychosocial and educational support from schools and communities.
\end{abstract}

Keywords: China; left-behind children; living quality; psychosocial health; remote city

\section{Introduction}

Nowadays, China has become the second largest economy body in the world. This prosperous economy has caused the largest migration in human history, which includes not only the migration from rural to urban areas but also the migration from remote cities to central cities. ${ }^{1}$ With millions of people immigrating to the central cities, looking for better income for their families, many children have been left behind by their migrant parents to live with their grandparents, other friends or relatives, or even on their own in their hometown. These children are usually called left-behind children (LBC). There is some evidence showing that these children experience more psychosocial and school difficulties and lower living quality than children who are raised by their own parents. The well-being of LBC has become a worrisome social issue in China. ${ }^{2-4}$ Most studies about Chinese LBC have been focused on the rural area, and little is known about the psychosocial health and living quality of the LBC in remote cities of China. To uncover the situation of these children, Children's Hope and Future Foundation (CHAFF) carried out a pilot survey about living quality and psychosocial health of 10- to 14-year-old children in a typical remote city, Guiyang, a Guizhou Province, which is located at Southwest China. The rank of gross domestic

${ }^{1}$ Washington Institute for Health Sciences, Arlington, Virginia.

${ }^{2}$ Georgetown University Medical Center, Washington, District of Columbia.

${ }^{3}$ Children's Hope and Future Foundation, Merrifield, Virginia.

*Address correspondence to: Bin Li, MD, Washington Institute for Health Sciences, 4601 North Fairfax Drive, Arlington, VA 22203, E-mail: bin.li@georgetown.edu

(c) Bin Li et al. 2017; Published by Mary Ann Liebert, Inc. This is an Open Access article distributed under the terms of the Creative Commons Attribution License, which permits unrestricted use, distribution, and reproduction in any medium, provided the original work is properly cited. 
product (GDP) level of this province is 25 th among the 31 provinces or municipalities in China.

CHAFF is a non-profit organization founded in 2010 in Virginia, the United States, that provides educational and assistive resources for children in need. The "Volunteering" Program is one of the most important projects in CHAFF, whose goal is to give the young generation an opportunity to learn, to nurture their responsibility to care and love others in need, and to raise awareness to the younger generation by letting them know that not every child is fortunate, and that there are a lot of children in need. The main objective of this preliminary study was to compare the emotional and behavioral problems and living quality of LBC in the Guiyang city with a random sample of children from the same region who were raised by their parents.

\section{Methods}

Subjects and procedure

The study was approved by the Internal Review Board at Washington Institute for Health Sciences, Arlington, Virginia, and CHAFF, Merrifield, Virginia. The appropriate permission from the school boards and the consent of the participants were obtained before all subjects were interviewed by using the instruments described in the section "Instruments". First, one elementary school and one middle school in Guiyang city were randomly selected, and then one class from fifth to ninth grade was also randomly selected to obtain a representative sample of students. A total of 45 valid subjects who either had a history of being left behind for more than 12 months or were raised by their own parents without interruption were included in the analysis of this article. The children and their teachers completed all the questionnaires during regular meetings organized by the school. The staff from CHAFF clarified the meaning of some questions to both children and their teachers.

\section{Instruments}

The Strength and Difficulties Questionnaire (SDQ): In this study, the one-sided Chinese version of SDQ was used for parents or teachers of 4- to 17-year-olds. ${ }^{5}$ The SDQ is a 25-item screening questionnaire that measures children and adolescents' psychosocial health in clinical practice, epidemiological settings, and developmental research. It is a widely used behavioral screening instrument developed by Goodman in 1997. ${ }^{6}$ Each item is scored from 0 (untrue), 1 (somewhat true), and 2 (certainly true). The items are divided into 5 subscales of 5 items, including emotional symp- toms, hyperactivity/inattention, conduct problems, peer problems, and prosocial behaviors. A total difficulty score is generated from summarizing the emotional symptoms, hyperactivity, conduct problems, and peer problems scores. The SDQ was completed by the children's class teacher.

Quality of Life Scale for Children and Adolescents (QLSCA): Living quality is a comprehensive evaluation that is used to summarize people's lives. It is a very broad concept that is not only related to the objective material conditions of life but also related to the degree of subjective satisfaction with life. In this pilot study, the QLSCA was used to evaluate the living quality of Chinese LBC. The QLSCA is a self-report that includes 49 items for children and adolescents from 7 to 18 years old. It was developed by the Department of Maternal Care and Child and Adolescents Health in Tongji Medical College of Huazhong University of Science and Technology, China, in 2000, and it was revised in $2002 .^{7}$ It is suitable for the multidimensional study on the quality of life of children and adolescents, and it is widely accepted in China. The QLSCA includes four major aspects: social psychology function (a total of 21 items covering teacher-student relationship, peer relation, parent-child relationship, learning ability and attitude, and self-concept), physiopsychological health (12 items covering somatic sensation, negative emotion, and attitude of homework), living environment (8 items covering life convenience, extracurricular activities, and athletic ability), and satisfaction of living quality ( 8 items), which are related to the learning and life of children and adolescents. Each item is scored from 1 (never), 2 (seldom), 3 (often), and 4 (always). The score for each issue and a total score are generated from summarizing the items in each issue and all items. The QLSCA was completed by the children.

\section{Education level assessment}

The education level of the caregivers and parents was ranked according to the highest level of education as follows: 0 (Illiteracy), 1 (primary school), 2 (middle school), 3 (high school), and 4 (college or higher).

\section{Statistical methods}

The data were analyzed by IBM SPSS version 24 . In this study, the demographic information between the LBC and the control group was summarized. The age and caregiver, father and mother's education level were presented in mean and standard deviation (SD). A two- 
Table 1. Demographics, Parents and Caregiver's Characteristics Between Left-Behind Children and Control Children

\begin{tabular}{|c|c|c|c|c|}
\hline & LBC $(n=19)$ & $\begin{array}{l}\text { Control } \\
\text { children } \\
(n=26)\end{array}$ & Statistics & $p$ \\
\hline $\begin{array}{l}\text { Children's age } \\
\qquad(\mathrm{M} \pm \mathrm{SD}) \text { (years) }\end{array}$ & $11.8 \pm 1.5$ & $12.0 \pm 1.4$ & $t=0.484$ & 0.631 \\
\hline \multicolumn{5}{|c|}{ Children's gender, $n$ (\%) } \\
\hline $\begin{array}{l}\text { Male } \\
\text { Female }\end{array}$ & $\begin{array}{l}46.2 \\
53.8\end{array}$ & $\begin{array}{l}47.4 \\
52.6\end{array}$ & $X^{2}=0.007$ & 0.936 \\
\hline $\begin{array}{l}\text { Caregiver's } \\
\text { education level } \\
(\mathrm{M} \pm \mathrm{SD})\end{array}$ & $0.4 \pm 0.6$ & $2.5 \pm 0.7$ & $t=10.146$ & $0.000^{* *}$ \\
\hline $\begin{array}{l}\text { Father's } \\
\text { education level } \\
(\mathrm{M} \pm \mathrm{SD})\end{array}$ & $2.5 \pm 0.6$ & $2.8 \pm 0.7$ & $t=1.411$ & 0.165 \\
\hline \multicolumn{5}{|c|}{$\begin{array}{l}\text { Composition of father's occupation before migration } \\
\text { in each group, } n(\%)\end{array}$} \\
\hline Farmer & 84.2 & 26.9 & $X^{2}=15.929$ & $0.001^{* *}$ \\
\hline Worker & 0.0 & 38.5 & & \\
\hline Merchant & 5.3 & 7.7 & & \\
\hline Officer & 10.5 & 26.9 & & \\
\hline $\begin{array}{l}\text { Mother's education } \\
\text { level }(M \pm S D)\end{array}$ & $2.2 \pm 0.5$ & $2.5 \pm 0.7$ & $t=1.687$ & 0.099 \\
\hline \multicolumn{5}{|c|}{$\begin{array}{l}\text { Composition of mother's occupation before migration } \\
\text { in each group, } n(\%)\end{array}$} \\
\hline Farmer & 84.2 & 15.4 & $X^{2}=21.566$ & $0.000^{* *}$ \\
\hline Worker & 5.3 & 53.8 & & \\
\hline Merchant & 5.3 & 11.5 & & \\
\hline Officer & 5.3 & 19.2 & & \\
\hline
\end{tabular}

${ }^{* *} p<0.01$.

LBC, left-behind children; M, mean; SD, standard deviation.

sided $t$-test was used to test the age equivalency between LBC and the control children. Gender and father and mother's occupation before migration were presented in numbers and percentages.

Chi-squares and $t$-tests were used to test the equivalency between the LBC and control children. The SDQ and QLSCA scores were presented in mean and SD. A two-sided $t$-test was used to test the score difference between LBC and the control children. The correlation between the SDQ, QLSCA scores and demographic information was presented in the Pearson correlation coefficient and related $p$-value. $p$-Values of $<0.05$ were considered statistically significant.

\section{Results}

\section{Demographics}

As a pilot study, a total of 45 children were included in the analysis. Demographic characteristics of LBC and control children are shown in Table 1 . There were no demographic (age and gender) differences between LBC and control children. The education level of the LBC's parents was slightly lower than that of the control children, but there was no significant difference. However, there were significant differences between the compositions of occupation before migration for the LBC and control children's parents. More than about $80 \%$ of the LBC's parents were farmers before migration, whereas most control children's parents were workers, merchants, and officers. The education level of the caregivers was significantly lower for the LBC than for the controls $(p<0.001)$.

\section{SDQ and QLSCA scores}

Table 2 presents the emotional and behavioral problems (SDQ scores) and living quality (QLSCA scores) of the LBC and control group. Based on the results, LBC had a significantly higher score in total difficulties score, emotional symptoms score, hyperactivity/

Table 2. Comparison of Strength and Difficulties Questionnaire and Quality of Life Scale for Children and Adolescents Score Between Left-Behind Children and Control Children

\begin{tabular}{|c|c|c|c|c|}
\hline & LBC $(n=19)$ & $\begin{array}{c}\text { Control } \\
\text { children }(n=26)\end{array}$ & Statistics & $p$ \\
\hline \multicolumn{5}{|l|}{ SDQ scores $(\mathrm{M} \pm \mathrm{SD})$} \\
\hline Total difficulties score (without prosocial) & $18.0 \pm 4.0$ & $13.9 \pm 3.8$ & $t=3.495$ & $0.001^{* *}$ \\
\hline Prosocial score & $6.7 \pm 1.3$ & $8.2 \pm 1.4$ & $t=3.668$ & $0.001^{* *}$ \\
\hline Emotional symptoms score & $4.8 \pm 1.2$ & $3.7 \pm 1.3$ & $t=2.980$ & $0.005^{* *}$ \\
\hline Hyperactivity/inattention score & $6.4 \pm 1.6$ & $4.9 \pm 1.7$ & $t=2.965$ & $0.005^{* *}$ \\
\hline Conduct problems score & $3.4 \pm 1.1$ & $2.5 \pm 0.9$ & $t=3.104$ & $0.003^{* *}$ \\
\hline Peer problems score & $3.2 \pm 1.4$ & $2.8 \pm 1.4$ & $t=1.306$ & 0.199 \\
\hline \multicolumn{5}{|l|}{ QLSCA scores $(M \pm S D)$} \\
\hline Total score of living quality & $119.2 \pm 13.0$ & $140.7 \pm 16.3$ & $t=4.754$ & $0.000^{* *}$ \\
\hline Social psychology function & $50.4 \pm 4.9$ & $59.9 \pm 7.4$ & $t=4.821$ & $0.000^{* *}$ \\
\hline Physiopsychological health & $36.1 \pm 3.4$ & $41.0 \pm 4.2$ & $t=4.269$ & $0.000 * *$ \\
\hline Living environment & $12.9 \pm 2.8$ & $15.6 \pm 2.9$ & $t=3.178$ & $0.003^{* *}$ \\
\hline Satisfaction of living quality & $19.8 \pm 3.2$ & $24.2 \pm 4.5$ & $t=3.598$ & $0.001^{* *}$ \\
\hline
\end{tabular}

${ }^{* *} p<0.01$.

QLSCA, Quality of Life Scale for Children and Adolescents; SDQ, Strength and Difficulties Questionnaire. 
Table 3. Correlation Between Children's Demographics and Scores of Strength and Difficulties Questionnaire and Quality of Life Scale for Children and Adolescents

\begin{tabular}{|c|c|c|c|c|c|}
\hline & Age & $\begin{array}{c}\text { Gender } \\
\text { (1: male, } \\
\text { 2: female) }\end{array}$ & $\begin{array}{l}\text { Caregiver's } \\
\text { education } \\
\text { level }\end{array}$ & $\begin{array}{l}\text { Father's } \\
\text { education } \\
\text { level }\end{array}$ & $\begin{array}{c}\text { Mother's } \\
\text { education } \\
\text { level }\end{array}$ \\
\hline \multicolumn{6}{|l|}{ SDQ scores } \\
\hline Total difficulties score & -0.118 & -0.185 & $-0.552^{* *}$ & $-0.547^{* *}$ & $-0.482^{* *}$ \\
\hline Prosocial score & 0.119 & 0.077 & $0.537^{* *}$ & $0.409^{* *}$ & $0.442^{* *}$ \\
\hline Emotional symptoms score & -0.130 & -0.281 & $-0.371^{*}$ & $-0.323^{*}$ & -0.241 \\
\hline Hyperactivity/inattention score & -0.062 & 0.040 & $-0.522^{* *}$ & $-0.563^{* *}$ & $-0.424^{* *}$ \\
\hline Conduct problems score & -0.249 & -0.233 & $-0.441^{* *}$ & -0.239 & $-0.317^{*}$ \\
\hline Peer problems score & 0.057 & -0.064 & $-0.388^{* *}$ & $-0.560^{* *}$ & $-0.534^{* *}$ \\
\hline \multicolumn{6}{|l|}{ QLSCA scores } \\
\hline Total score of living quality & 0.030 & 0.026 & $0.734^{* *}$ & $0.719^{* *}$ & $0.622^{* *}$ \\
\hline Social psychology function & 0.127 & 0.021 & $0.673^{* *}$ & $0.628^{* *}$ & $0.524^{* *}$ \\
\hline Physiopsychological health & 0.030 & 0.114 & $0.725^{* *}$ & $0.634^{* *}$ & $0.599 * *$ \\
\hline Living environment & -0.052 & -0.147 & $0.603^{* *}$ & $0.661^{* * *}$ & $0.570^{* *}$ \\
\hline Satisfaction of living quality & -0.098 & 0.055 & $0.635^{* *}$ & $0.708^{* *}$ & $0.599^{* *}$ \\
\hline
\end{tabular}

${ }^{*} p<0.05,{ }^{* *} p<0.01$.

inattention score, and conduct problems score than in the control group with $p$-values that were all $<0.01$. The prosocial score in LBC was significantly lower than that of the control children $(p<0.01)$. The scores on total QLSCA, social psychology function, physiopsychological health, living environment, and satisfaction of living quality were significantly lower for the LBC than for their counterparts $(p<0.01)$.

The correlation between children's demographics and scores of SDQ and QLSCA

Table 3 shows the correlation results between the children's demographics and scores of SDQ and QLSCA. From the results, we found that there were significant correlations between the education levels of caregiver, father, and mother and scores of SDQ and QLSCA. The total difficulty score, emotional symptoms score, hyperactivity symptoms score, conduct problems score, and peer problems score were inversely correlated with the caregiver and parents' education levels $(p<0.01)$. On the other hand, the prosocial behavior score was positively associated with the parents and caregiver's education level $(p<0.01)$. The scores on total QLSCA, social psychology function, physiopsychological health, living environment, and satisfaction of living quality were significantly positively associated with parents and caregiver's education level $(p<0.01)$

\section{The correlations between children's SDQ score} and QLSCA score

Table 4 shows the correlations between children's SDQ and QLSCA scores. The results indicate that emotional and behavioral problems and living quality are highly correlated, except for the correlation between the living environment score and the conduct problems score.

\section{Discussion}

This pilot study examines the psychosocial health and the living quality of LBC in a remote city of Southwest China with the SDQ teacher version and QLSCA. The results show that LBC have more emotional and behavioral problems, less prosocial behaviors, and lower living quality than the non-left-behind control children. Our findings in this study correspond to the results

Table 4. Correlations Between Children's Strength and Difficulties Questionnaire Score and Quality of Life Scale for Children and Adolescents

\begin{tabular}{|c|c|c|c|c|c|}
\hline & $\begin{array}{c}\text { Total score } \\
\text { of living } \\
\text { quality }\end{array}$ & $\begin{array}{c}\text { Social } \\
\text { psychology } \\
\text { function }\end{array}$ & $\begin{array}{l}\text { Physiopsychological } \\
\text { health }\end{array}$ & $\begin{array}{l}\text { Living } \\
\text { environment }\end{array}$ & $\begin{array}{c}\text { Satisfaction } \\
\text { of living } \\
\text { quality }\end{array}$ \\
\hline Total difficulties score & $-0.794^{* *}$ & $-0.752^{* *}$ & $-0.741^{* *}$ & $-0.626^{* *}$ & $-0.712^{* *}$ \\
\hline Prosocial score & $0.655^{* *}$ & $0.680^{* *}$ & $0.527^{* *}$ & $0.508^{* *}$ & $0.573^{* *}$ \\
\hline Emotional symptoms score & $-0.758^{* *}$ & $-0.683^{* *}$ & $-0.725^{* *}$ & $-0.697^{* *}$ & $-0.653^{* *}$ \\
\hline Hyperactivity/inattention score & $-0.615^{* *}$ & $-0.598^{* *}$ & $-0.536^{* *}$ & $-0.465^{* *}$ & $-0.574^{* *}$ \\
\hline Conduct problems score & $-0.483^{* *}$ & $-0.505^{* *}$ & $-0.495^{* *}$ & -0.255 & $-0.390^{* *}$ \\
\hline Peer problems score & $-0.570^{* *}$ & $-0.513^{* *}$ & $-0.527^{* *}$ & $-0.480^{* *}$ & $-0.542^{* *}$ \\
\hline
\end{tabular}

${ }^{* *} p<0.01$. 
reported in many related studies about LBC in rural areas of China. ${ }^{2,3,8}$

The Pearson correlation test shows that lower education levels of parents and caregivers are associated with an increased risk for emotional and behavioral problems, less prosocial behaviors, and lower living quality. In general, lower education level causes lower household income. The children from families with lower education levels have less resources and support. ${ }^{9}$ In addition, the caregivers with lower education level provide insufficient support for the children, which causes the children to have more emotional and behavior problems. $^{3}$

This study shows that the composition of parents' occupation before migration caused significant differences between LBC and control children. More than eighty percent of LBC's parents were farmers before migration. On the contrary, only less than thirty percent of control children's parents were farmers. With the development of economy, cities started expanding. Many farmers who lived in the suburbs of cities lost their land and became city residents. Even though they could get compensation for the loss of land, they lacked the necessary skills to make a living in the cities. Therefore, many of them had to move from the poorer remote cities to the central cities and manufacturing hubs to find better jobs. That is why according to this study a high proportion of LBC's parents were farmers before migration. When the children were left behind, they had to be taken care of by other caregivers. Our data show that the primary caregivers for LBC are their grandparents, and generally they have lower education levels. This result corresponds to Ye et al.'s study, in which they found that children taken care of by their grandparents tend to have more psychosocial problems, because the grandparents generally paid more attention to children's physical satisfaction and less attention to children's psychosocial health. ${ }^{10}$

In this study, we found that the children's emotional and behavioral problems and QLSCA score for living quality are highly correlated. According to Jia et al.'s study, psychosocial problems rather than physical ones accounted more for the lower living quality. They concluded that any situations that affect the children's emotional and social functioning would be regarded as risk factors for lower living quality in LBC. ${ }^{11}$ Therefore, we believe that the LBC in remote cities need more psychosocial and educational support from schools and communities.
Some limitations in this study should be recognized. First, we were only able to collect 45 valid cases in this pilot study due to the limited resources. However, we are planning to collect more cases in the future. Second, it is better to include more demographic information, such as household income, parental psychopathology, and family relationships, in the survey. Finally, this is only a cross-sectional study; therefore, we can only evaluate the correlation between variates rather than the causation. A longitudinal study may help to assess the causation for the effects of the left-behind and intervention approach. However, this pilot study provides important preliminary information about the LBC in a remote city of China, which can guide the study in future.

\section{Conclusion}

In summary, the rapid economic development in China has been accompanied by a large amount of people leaving their hometown and moving to the big cities for seeking better incomes, which leaves a large proportion of LBC who experience lack of parents' care. This preliminary study identified the severity of the psychosocial problem and the lower living quality with LBC in remote cities. We believe that spiritual care and educational assistance may improve the psychosocial health and living quality of LBC. CHAFF, as a charitable organization, aimed at providing educational and assistive resources for children in need, planned to continue this study with a larger population in future, and also included a study focusing on the effect of educational assistance on LBC. We expect our study to be informative for the development of strategies to promote the well-being of LBC.

\section{Acknowledgment}

The research in this article was supported by the Children's Hope and Future Foundation.

\section{Author Disclosure Statement}

No competing financial interests exist.

\section{References}

1. Zhang QF. Economic transition and new patterns of parent-adult child coresidence in urban China. J Marriage Fam. 2004;66:12311245.

2. Huang Y, Zhong XN, Li QY, et al. Health-related quality of life of the rural-China left-behind children or adolescents and influential factors: a cross-sectional study. Health Qual Life Outcomes. 2015; 13:29-39.

3. Fan F, Su L, Gill MK, et al. Emotional and behavioral problems of Chinese left-behind children: a preliminary study. Soc Psychiatry Psychiatr Epidemiol. 2010;45:655-664. 
4. Dai Q, Yang G, Hu C, et al. The alienation of affection toward parents and influential factors in Chinese left-behind children. Eur Psychiatry. 2017;39:114-122.

5. Youthinmind Ltd. One-sided SDQ for parents or teachers of 4-17 year olds. Available at www.sdqinfo.com/py/sdqinfo/ b3.py?language=Chinese Accessed March 12, 2017.

6. Goodman R. The Strengths and Difficulties Questionnaire: a research note. J Child Psychol Psychiatry. 1997;38:581-586.

7. Chen L, Wu H, Mai J, et al. Comparison of quality of life among primary and secondary school students between urban and rural in Beijing and Guangzhou. Chin J Integr Med. 2007;24:268-270.

8. Wang L, Mesman J. Child development in the face of rural-to-urban migration in China: a meta-analytic review. Perspect Psychol Sci. 2015;10:813-831.

9. Brooks-Gunn J, Duncan GJ. The effects of poverty on children. Future Child. 1997;7:55-71.

10. Ye, J, Murray J, Wang Y. Left-Behind Children in Rural China. Beijing, China: Social Sciences Academic Press, 2005.

11. Jia Z, Shi L, Cao Y, et al. Health-related quality of life of "left-behind children": a cross-sectional survey in rural China. Qual Life Res. 2010;19:775-780.
Cite this article as: Li B, Chu S, Zhong $\mathrm{H}$ (2017) A pilot study on the psychosocial health and living quality of left-behind children in a remote city of China, Health Equity 1:1, 103-108, DOI: 10.1089/ heq.2017.0019.

Abbreviations Used
CHAFF $=$ Children's Hope and Future Foundation
$\mathrm{LBC}=$ left-behind children
$\mathrm{QLSCA}=$ Quality of Life Scale for Children and Adolescents
$\mathrm{SD}=$ standard deviation
$\mathrm{SDQ}=$ Strength and Difficulties Questionnaire

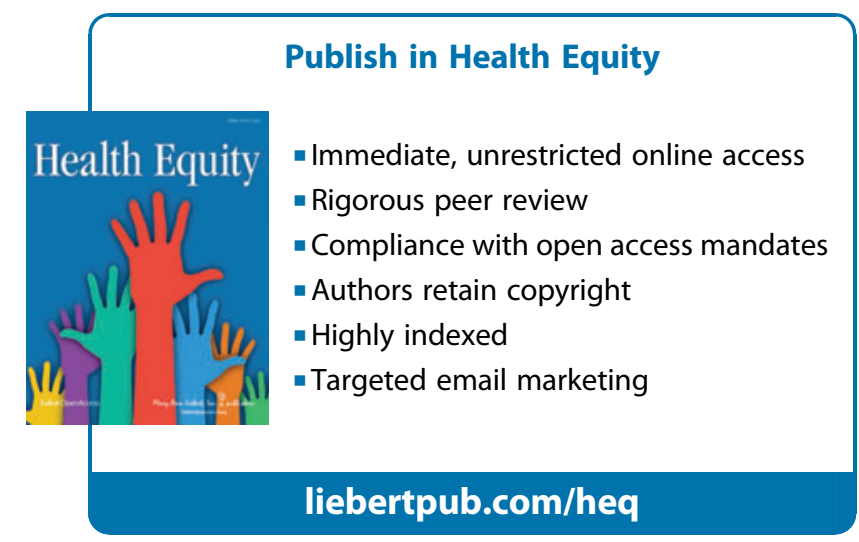

